\title{
Commentary on the decision of the American Board of Medical Genetics and Genomics to create a 24-month specialty of Laboratory Genetics and Genomics
}

\author{
Frederick R. Bieber, PhD'1, Athena M. Cherry, PhD1, Beverly S. Emanuel, PhD', Uta Francke, MD, \\ H. Eugene Hoyme, MD1, Laird G. Jackson, MD ${ }^{1}$, Cynthia C. Morton, PhD ${ }^{1}$, Maximillian Muenke, MD ${ }^{1}$, \\ Cynthia M. Powell, MD, MS'1, Hope H. Punnett, PhD¹, P. Nagesh Rao, PhD¹, Stuart Schwartz, PhD', \\ Roger E. Stevenson, $\mathrm{MD}^{1}$ and Daniel L. Van Dyke, $\mathrm{PhD}^{1}$
}

On 16 May 2016, a letter was sent to the diplomates of the American Board of Medical Genetics and Genomics (ABMGG) in which their current Board of Directors (BOD) announced that "the ABMGG has decided to merge the training of cytogenetics and molecular genetics into a single specialty named Laboratory Genetics \& Genomics (LGG)" that would require just 24 months of fellowship with no time allotted for research. ${ }^{1}$ The explanation for this decision was that this merger would help ensure that those who complete fellowship programs would be able to effectively utilize, integrate, and accurately interpret data from some of the newer techniques shared by both clinical cytogeneticists and clinical molecular geneticists, such as genomic copy-number microarrays and next-generation sequencing.

Although we-all former members of the BOD of the ABMGG who hold certificates in Clinical Cytogenetics-favor a merger of the training experience of clinical cytogenetics and clinical molecular genetics, we strongly oppose the decision of the current $\mathrm{BOD}$ to reduce the required length of training to 24 months. We are unanimous in our conviction that 24 months is insufficient to prepare trainees adequately to serve the needs of their future patients, and we find it most disconcerting that the ABMGG BOD has initiated an abbreviated training program without an open discussion among diplomates. The views and concerns described herein are shared by most of the genetics colleagues with whom we have discussed this matter. Indeed, the increasing complexity of clinical and laboratory diagnostic genetic testing requires more time, not less, and demands inclusion of required research time in training programs to prepare future medical geneticists best for leadership roles in or out of academic medical genetics settings.

In addition to our opposition to an abbreviated fellowship program, the proposed new name of Laboratory Genetics \& Genomics fails to suitably emphasize the clinical nature of this specialty. To add to this confusion, the ABMGG website (FAQ, updated August 2016) states that this LGG program allows up to 6 months of an undefined "area of concentration." This further reduces the general training to 18 months and makes it impossible to distinguish a fellow who achieves "LGG" certification as having a focus in either field at a time when cytogenetics and molecular genetics technologies are merging into a single clinical specialty.

Accordingly, we urge the ABMGG BOD to act quickly to require 36 months of training for this new ABMGG specialty, which is in keeping with current requirements for those who have heretofore sought certification in both clinical cytogenetics and clinical molecular genetics. This will require the BOD to reverse its decision to institute a 24-month plan for the combined program. The ABMGG must begin anew to design a clinical laboratory specialty or specialties while enlisting the help and support of current clinical biochemical, clinical cytogenetics, and clinical molecular genetics diplomates, especially those who are engaged in clinical laboratory genetics education and practice. A title or designation other than Laboratory Genetics \& Genomics should be chosen that is more suitable, incorporates the increasingly important nonlaboratory aspects of the work of medical geneticists (e.g., genome sequence analysis and interpretation), and appropriately distinguishes it from the already existing ABMGG specialty of Clinical Genetics. Either all fellows in this newly envisioned program will receive similar education and training, and then will be prepared to receive the same ABMGG certificate, or they will not, and there should be separate certificates.

The large amount of data generated by exome and genome sequencing require further exposure to new aspects of informatics and big data analysis. ${ }^{2}$ These aspects relate to all areas of medical genetics, whether they be clinical, cytogenetic, molecular, or biochemical. Pathologists have recognized this and, accordingly, have added additional fellowship training (the subspecialty of Molecular Genetic Pathology) beyond the 3-4 years of traditional anatomic or clinical pathology residency programs. ${ }^{3,4}$ This is especially relevant in light of the

${ }^{1}$ Mayo Clinic Cytogenetics Laboratory, Rochester, Minnesota, USA. Correspondence: Daniel L. Van Dyke (VanDyke.Daniel@mayo.edu)

Submitted 6 September 2016; accepted 9 September 2016; advance online publication 17 November 2016. doi:10.1038/gim.2016.171 
increasing interest by pathologists in assuming responsibility for all genetic testing, including whole-genome sequencing. ${ }^{5}$

In addition to a comprehensive understanding of heritable genetic disorders, much of the current genetic testing relates to hematology and oncology, and this testing will only increase in volume and complexity. Clinical laboratory geneticists will be expected to have an understanding of the fundamentals of tumorigenesis, disease progression, and prognosis as they relate to evolving therapeutic options. This is in addition to traditional mastery of concepts relating to the diversity of lethal and heritable genetic diseases, reproductive risks, and the critical importance of accurate prenatal genetic testing.

To address these complex needs, a properly designed clinical diagnostic laboratory genetics fellowship requires a broad, extensive core curriculum embracing the full breadth of didactic education in medical genetics, self-driven academic work (research) including oral and written presentations, comprehensive rotations within the clinical cytogenetics and clinical molecular genetics laboratories (e.g., quality assurance, quality improvement, specimen accessioning, cell culture and DNA and RNA purification, and test validation, through to communication of results to the client and patient) as well as in medical genetics clinics (including prenatal screening and diagnosis, dysmorphology, and adult onset genetic conditions), andespecially for $\mathrm{PhD}$ fellows-significant exposure to the critical interface between hematopathology, surgical and autopsy pathology, and the medical genetics clinic. All future clinical laboratory genetics fellows must acquire the ability to interpret genomic test results in terms of implications and mechanisms of structural variations in the genome and will face the challenge of evaluating structural genomic rearrangements both in describing them and in predicting their phenotypic implications, allowing them to make meaningful clinical interpretations based on the three-dimensional structure of the genome in patient samples with disrupted chromatin domains. ${ }^{6}$ Biochemical genetics might also be carefully considered in training programs because many aspects of this field are also merging with genomics. Such knowledge cannot be mastered in 24 months.

We hold the view that clinical research is an essential component of any medical genetics fellowship program. Most other American Board of Medical Specialties (ABMS) specialties provide residents and fellows with committed research time; in our quickly evolving field of medical genetics, this research experience is arguably even more important. Accordingly, we believe that 36 months is required if a combined clinical cytogenetics/clinical molecular genetics fellowship is to be created (excluding physicians who have successfully completed another ABMS specialty and might be permitted to complete this training in 2 years). Defined research time allows formulation of a hypothesis, design of experiments based on a clinical question, and the chance to validate methodological improvements or develop new clinical testing protocols.

The benefits of a 3-year fellowship program, with research time, for the fellow-mentor research relationship cannot be overemphasized because fellows work on research projects and see the results through to presentation at a national meeting and to peer-reviewed publications. Without research time, the clinical laboratory genetics fellow will likely have no publications, national meeting abstracts, opportunity to network, or a story to tell other than that they completed many rotations during a 24-month program. The ABMGG must incorporate these research relationships into the formal fellowship requirements for the betterment and longevity of our profession. Otherwise, who will be the future academic leaders of our profession?

Funding remains a serious concern because genetics competes with other specialties for institutional funding. The need for continued funding of these programs remains a challenge if this career path is to remain viable. Program directors will need support to seek institutional funds to support a 3-year program and attract the most talented fellows. If the ABMGG requires only 24 months for a combined program, the decision will quickly lead to the loss of the 36-month option for simple fiscal reasons relating to local departmental and institutional budgets. We have already experienced this challenge at our own institutions. There is a real and present danger that, no matter the source of funding (ACGME residency funds or external research-sourced funds), the institutional unit controlling those funds will limit clinical laboratory genetics fellowships to 24 months. The BOD must move quickly to rethink its decision. The very future of this field is at stake and clearly there is work to do. We stand ready to help.

The authors of this Commentary, all former members of the ABMGG BOD, are listed below with their ABMGG certifications. Frederick R. Bieber, PhD: PhD Medical Genetics 1982, Clinical Cytogenetics 1987, Clinical Molecular Genetics 1993; Athena M. Cherry, PhD: Clinical Cytogenetics 1993; Beverly S. Emanuel, PhD: PhD Medical Genetics 1982, Clinical Cytogenetics 1982; Uta Francke, MD: Clinical Cytogenetics 1982, Clinical Genetics 1982, Clinical Molecular Genetics 1993; H. Eugene Hoyme, MD: Clinical Genetics 1984, Clinical Cytogenetics 1987; Laird G. Jackson, MD: Clinical Genetics 1982, Clinical Cytogenetics 1982; Cynthia C. Morton, PhD: PhD Medical Genetics 1984, Clinical Cytogenetics 1984, Clinical Molecular Genetics 1993; Maximillian Muenke, MD: Clinical Genetics 1990, Clinical Cytogenetics 1990, Clinical Molecular Genetics 1993; Cynthia M. Powell, MD, MS: Clinical Genetics 1993, Clinical Cytogenetics 1993; Hope H. Punnett, PhD: PhD Medical Genetics 1984, Clinical Cytogenetics 1984; P. Nagesh Rao, PhD: Clinical Cytogenetics 1990; Stuart Schwartz, PhD: PhD Medical Genetics 1984, Clinical Cytogenetics 1984, Clinical Molecular Genetics 1993; Roger E. Stevenson, MD: Clinical Genetics 1982, Clinical Cytogenetics 1984; Daniel L. Van Dyke, PhD: PhD Medical Genetics 1982, Clinical Cytogenetics 1982.

\section{DISCLOSURE}

The authors declare no conflict of interest.

\section{REFERENCES}

1. Sutton VR, Blitzer MG. American Board of Medical Genetics. Letter to diplomates, 16 May 2016 http://abmgg.org/pdf/LGG_Announcement.pdf. Accessed 5 September, 2016.

2. Dong Z, Zhang J, Hu P, et al. Low-pass whole-genome sequencing in clinical cytogenetics: a validated approach. Genet Med 2016;18:940-948. 


\section{COMMENTARY}

3. Walk EE. The role of pathologists in the era of personalized medicine. Arch Pathol Lab Med 2009;133:605-610.

4. Haspel RL, Arnaout R, Briere L, et al. A call to action training pathology residents in genomics and personalized medicine. Amer J Clin Path 2010;133: 832-834.
BIEBER et al | ABMGG to create a specialty of Laboratory Genetics and Genomics

5. Park JY, Leung ST, Wang J. Licensure in the era of genomic medicine. Arch Pathol Lab Med 2016;140:623-624.

6. Lupiáñez DG, Kraft K, Heinrich V, et al. Disruptions of topological chromatin domains cause pathogenic rewiring of gene-enhancer interactions. Cell 2015;161:1012-1025 